Med Klin Intensivmed Notfmed 2015 • 110:602 DOI 10.1007/s00063-015-0055-6

Online publiziert: 11. August 2015

(c) Springer-Verlag Berlin Heidelberg 2015
T. Schlögl • J. Schwab · M.A. Weber · B. Witzenbichler · M.A. Russ

Klinik für Innere Medizin I, Helios-Amperklinikum Dachau, Dachau, Deutschland

\section{Erratum zu: Milde therapeutische Hypothermie}

Erratum zu:

Med Klin Intensivmed Notfmed (2015)

doi:10.1007/s00063-015-0023-1

In der zunächst veröffentlichten OnlineVersion des Beitrags wurden bei der Bearbeitung im Verlag in der Legende von - Abb. 4 leider die Farben vertauscht.

Die Redaktion bittet, den Fehler zu entschuldigen und um Beachtung der korrekten Version.

\section{Korrespondenzadresse}

\section{M.A. Russ}

Klinik für Innere Medizin I

Helios-Amperklinikum Dachau

Krankenhausstr. 15, 85221 Dachau

martin.russ@posteo.de

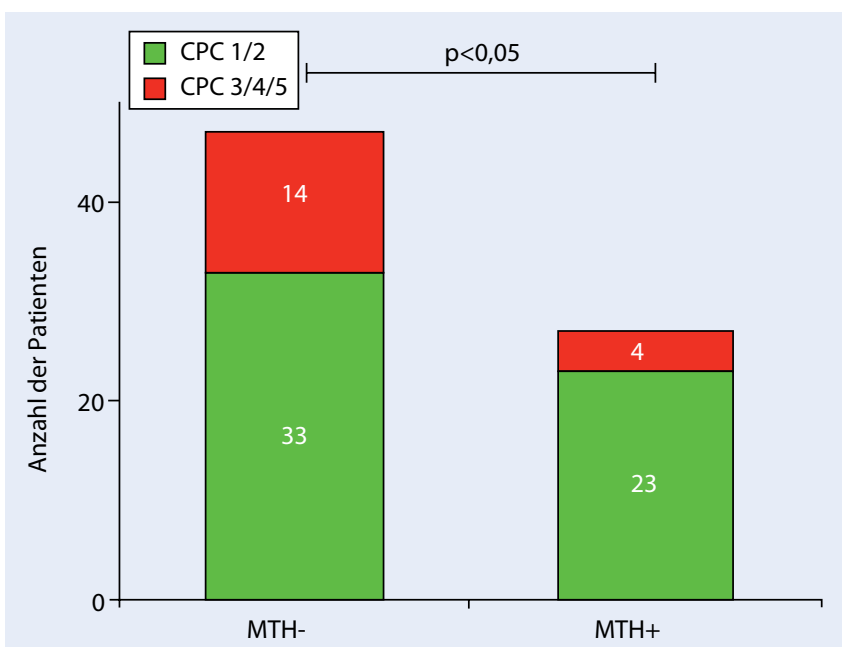

